\title{
Local treatment of burn wounds in animals using a new nanocomponent ointment
}

\author{
Natalia Fedota ${ }^{1}$, Eduard Gorchakov ${ }^{1, *}$, Bagama Bagamaev ${ }^{1}$, Ivan Kireev $^{1}$, Valeriya \\ Shahova ${ }^{1}$, Vladimir Kolodkin ${ }^{2}$ \\ ${ }^{1}$ Stavropol State Agrarian University, 355017 Zootekhnicheskiy per., 12, Stavropol, Russia \\ ${ }^{2}$ Don State Technical University, Gagarin sq., 1, 344000, Rostov-on-Don, Russia
}

\begin{abstract}
We have developed an ointment preparation consisting of silver and zinc oxide nanoparticles, which form the basis of the nanocomposition. This drug can reduce the healing time of the wound surface due to the inclusion of nanodispersed particles in the composition. Application of nanoparticles allows to reduce inflammatory process, to carry out disinfecting treatment of a wound surface from pathogenic microorganisms, and accordingly to create optimum conditions for reparative process. Nanocomposite preparation has many advantages over existing analogues without irritating and allergic effects. Due to the high adsorption capacity, it allows to accelerate the healing process of the damaged surface of the skin. Initial studies were conducted on laboratory rats at the age of 6 months with a close mass that was up to $250 \mathrm{~g}$ in accordance with international requirements for the use of laboratory animals. As a result of the experiment, a new ointment preparation based on silver and zinc oxide nanoparticles, which are active components of the nanocomposition, was obtained. The use of these components allowed to accelerate the process of reparative restoration of the skin with full recovery of the studied animals. As shown by the experience, the recovery rate on average accelerated by seven days, compared with similar drugs available on the pharmaceutical market.
\end{abstract}

\section{Introduction}

Nanotechnology may prove to be actual in many fields of medical science, including traumatology, one of the major problems of which is the widespread increase in injuries of various etiology; an important place thereof takes skin breakdown, in particular, burn wounds.

\footnotetext{
*Corresponding author: gorchakovedvard@mail.ru
} 
Recent studies have proved the effectiveness of nanoparticle-based drugs use, as the nanostructured particles ensure an equal increase in drug concentration in blood and tissues, even deeply penetrating body's natural barriers such as skin and blood-brain barriers, producing high drug dose in lesions, providing an optimal therapeutic effect, and having a powerful antibacterial, bacteriostatic and antiviral effect. Silver-based drugs do not cause resistance with the majority of pathogens, they are low-toxic, hypoallergenic, and also have immunocorrecting properties [1-7].

Various methods are used for silver nanoparticles synthesis, but the most commonly used method is based on the reduction of silver ions in solutions using various reducing agents. Such method is widespread due to its simplicity and availability [7-10]. This method was used in our study as well.

The perspective of the development and the medical use of substances containing zinc oxide nanoparticles, the preparations whereof have high antibacterial and photocatalytic properties, is of considerable interest $[5,6]$. There is fragmentary information about zinc nanoparticles producing anti-sclerotic effect, i.e. promoting the correction of microelement exchange at the tissue level, protecting the cells from the damaging action of enzymes, accelerating the healing of vast burn wounds by $15-20 \%$, affected by the use of $10 \%$ zinc ointment, and about other quality indicators.

The primary objective of our study was to develop nanocomponent ointment compositions for the treatment of open mechanical injuries, contributing to the stimulation of wounds, burns and other skin damage healing. Zinc oxide and elementary silver based nanoparticles have been chosen as the study subject. The result of the study shall be the development of an innovative high-efficient wound healing drug for the treatment of the wound injuries of various etiology, made in the form of a semisolid.

\section{Materials and methods}

\subsection{Preparation nanoparticles}

Synthesis of nanoparticles was carried out according to the technique described [4, 7$10]$.

The main characteristics of the synthesized nanoparticles were determined by electron microscopy, Polydispercity and their corresponding size in the sample was confirmed by absorption spectra [8-10].

\subsection{Synthesis of ointment compositions}

\section{Example 1.}

Pharmaceutical hydrophilic ointment composition was prepared as follows. The required quantity of methyl cellulose (Mc-100) was mixed with distilled water and left to swell for 40 minutes. Then, with constant stirring, the required quantity of colloidal zinc oxide $(\mathrm{ZnO})$, glycerin, and colloidal silver were added in the developed gel, followed by physicochemical effect for preventing destabilization processes and aggregation of $\mathrm{ZnO}$ and $\mathrm{Ag}$ particles. The received ointment composition represents the 
unscented homogeneous (free of particles) white or yellow ointment with neutral $\mathrm{pH}$ reaction $(\mathrm{pH} \approx 7)$. The result is the hydrophilic pharmaceutical ointment composition with the following equivalence ratio in wt $\%$ :

$\begin{array}{ll}\text { Colloidal silver } & <0.0001 \\ \text { Colloidal zinc oxide } & 3 \\ \text { Glycerin } & 3 \\ \text { Methyl cellulose } & 0.02 \\ \text { Water } & \text { remaining }\end{array}$

\section{Example 2}

The ointment is prepared similar to those in Example 1, but with the following equivalence ratio in wt $\%$ :

$\begin{array}{ll}\text { Colloidal silver } & 0.0001-0.1 \\ \text { Colloidal zinc oxide } & 10 \\ \text { Glycerin } & 10 \\ \text { Methyl cellulose } & 0.1 \\ \text { Water } & \text { remaining }\end{array}$

\section{Example 3}

The ointment is prepared similar to those in Example 1 and Example 2, but with the following equivalence ratio in wt $\%$ :

$\begin{array}{ll}\text { Colloidal silver } & 0.6 \\ \text { Colloidal zinc oxide } & 15 \\ \text { Glycerin } & 15 \\ \text { Methyl cellulose } & 5.5 \\ \text { Water } & \text { remaining }\end{array}$

\subsection{Therapeutic efficacy determination}

Study objective: examination of wound healing effect of a new ointment composition with the inserted complex compounds of silver and zinc nanoparticles on burn healing process behavior. Experimental animals studies have been conducted in compliance with the requirements of Guide for the Careand Use of Laboratory Animals and the Russian legislation [11].

The experiment on the study of the effect of the developed pharmaceutical hydrophilic ointment compositions on burn healing process behavior was conducted in Wistar rats aged from 6 months, weighing up to 250 grams. The animals were kept in the same conditions of the vivarium on a standard feeding schedule. Six groups of ten animals in each were formed for the study:

1 group, the wound surface of which was treated with the ointment composition in accordance with Example 1;

2 group - the ointment composition in accordance with Example 2;

3 group - the ointment composition in accordance with Example 3;

4 group - $10 \%$ zinc ointment (OOO Firm "BioChimFarm", Vladimir Oblast, 
Raduzhniy);

5 group $-2 \%$ Argosulfan (Jelfa S.A. (Poland) and OOO "Valeant" (Russia));

6 group - Control;

The duration of the experience was 21 days, 7 of which the animals were kept in quarantine. Skin areas of $4 x 4 \mathrm{~cm}$ on the side body surface have been shaved clean with a safety razor 24 hours prior to the thermal burn modeling. The preliminary subcutaneous injection of $5-10 \mathrm{ml} 0.9 \% \mathrm{NaCl}$ has been made for the convenience of shaving - skin then stretched and there were no any damages.

Thermal burn modeling was made in accordance with the standard practice [12]. While burning, an empty glass tube with inner diameter of $22 \mathrm{~mm}$ (sectional area $4 \mathrm{~cm}^{2}$ ) and length of $15 \mathrm{~cm}$ was filled with hot water, placed vertically in boiling water for $2 / 4$ of its height, heated during 1 one minute, filled through its top for $2 / 3$ of its height, and was vertically placed into contact with the animal's shaved skin area for 10 seconds. Its area was about $8-9 \%$ of the whole body surface. For calculation of its value with a rat, the formula offered by Mich was used reference (1):

$$
\mathrm{S}=\mathrm{k} \times 2 / 3 \mathrm{~W},
$$

where $\mathrm{S}$ - body sufrace, $\mathrm{cm}^{2}, \mathrm{~W}$ - animal's body weight, $\mathrm{kg}, \mathrm{k}-$ Mich constant (9.46).

As a reaction to the operation, in accordance with C.Kreibich international classification [13], IV-degree burns appeared with an average size of $1 \times 1 \mathrm{~cm}$. The procedure was conducted under general anesthesia with the use of Zoletil 50 as an anesthetic.

The appearing III B burns had a round form, the wound bed was bright red, with brown areas. The wound edges represented slightly hanging soft tissues parts of red and brown color. Hyperemia area was registered around the wound with width of $0.5-0.8$ $\mathrm{cm}$. The examination of experimental animals, wound surface cleaning were carried out daily, twice a day, and wound repair indexes were fixed. During the experimental period, control of the burn surface was made on the 1, 3, 5, 10 and 14 days. The tested substances were used in a dose of $10 \mathrm{mg} / \mathrm{cm}^{2}$. Saline was used as a reference substance.

For the assessment of the effectiveness of our drug, an everyday decrease in the wounds area was estimated on a percentage basis with regard to the first day of the experiment. Considering individual variations, the relative index - relative healing value $\left(\mathrm{Y}_{1}\right)$ was used for the received data processing, which is determined according to a formula (2) [12]:

$$
\mathrm{Y}_{1}=\left(\mathrm{S}_{0}-\mathrm{S}_{1}\right) / \mathrm{S}_{1},
$$

where $S_{0}$ - initial wound area; $S_{1}$ - its area on day $t$.

\section{Results}

The following day after the burn modelling the observation over the study subjects was 
conducted.

On the third day, with animals of all the examination groups the partial eschar rejection on the edge of the wound surface was registered, under which the formation of a young granulation tissue is observed. Besides, a leucocytic infiltration of the involved tissues was registered near the wound defect, in particular in the tissue death site. Along the wound edges a mild epithelialization was visible 51. Demarcation lines around the wounds in groups 1-3 were within 2-3 $\mathrm{mm}$. The slowest reparative regeneration processes were registered in groups 4,5 and 6 . The demarcation line was within 4-6 $\mathrm{mm}$, and in the fourth group it reached $8 \mathrm{~mm}$.

By the fifth day the majority animals in the experimental groups had regeneration processes improvement. The reduction of burn wound area and incomplete eschar rejection in the wound bed area were observed. In groups 1, 3, 4, 5 and 6 all animals instead of the eschar crust had deep wounds developed, at the edge of which the necrobiosis processes with the development of hydropic degeneration was seen in the epithelium. The cast hyperemia area is registered around the wound defect. In group 4, where the animals have been treated with zinc ointment applications, surrounding tissues vast irregular oedema up to $25 \mathrm{~mm}$ in diameter, with unclear edges, was regisesred around the wounds.

By the sixth day in groups $1-3$ the rejection of the burn eschar took place. The eschar in the experimental groups was dry and thin. Regeneration processes were in action. Complete epithelization of the wound defect was registered without concentric wound contraction development.

By the tenth day, the wound defect bed of the animals from groups $1-3$ was clean and pink. The wound bed in the rest groups was deep and irregular, the eschar hardly removed reparation processes were slow and carried the risk of concentric contraction and scars development. The fourth group showed the vast hyperemia area around the wound.

By the 14th day, the burn wounds area was reduced in all groups (tabl. 1):

1 group - hydrophilic pharmaceutical ointment composition in accordance with Example 1 - by $90.5 \%$;

2 group - hydrophilic pharmaceutical ointment composition in accordance with Example 2 - by $92.8 \%$;

3 group - hydrophilic pharmaceutical ointment composition in accordance with Example 3 - by $86.6 \%$;

4 group - Zinc ointment - by $69.7 \%$;

5 group - Argosulfan - by $71.8 \%$;

6 group - Control - by $60.7 \%$.

The final and complete burn wounds healing of rats from groups 1-3 was registered at the 16th - 18th day, in groups 4 and 5 - at the 22nd and 19th day of the experiment correspondingly, in the control group - at the 29th day.

Table 1. Burn wounds area affected by the use of various drugs 


\begin{tabular}{|c|c|c|c|c|c|c|c|}
\hline & $\begin{array}{r}\text { Group nande } \\
\text { Experim., } \\
\text { days }\end{array}$ & $1^{\text {st }}$ & $3^{\text {rd }}$ & $5^{\text {th }}$ & $10^{\text {th }}$ & $14^{\text {th }}$ & $\begin{array}{l}\text { Healing } \\
\text { level at } \\
\text { the } 14^{\text {th }} \\
\text { day, } \%\end{array}$ \\
\hline 1 & Example 1 & $2.55 \pm 0.31$ & $2.21 \pm 0.44$ & $1.30 \pm 0.22$ & $0.40 \pm 0.05$ & $0.24 \pm 0.04$ & 90.5 \\
\hline 2 & Example 2 & $2.24 \pm 0.09$ & $1.56 \pm 0.12$ & $1.00 \pm 0.14$ & $0.25 \pm 0.31$ & $0.16 \pm 0.03$ & 92.8 \\
\hline 3 & Example 3 & $2.25 \pm 0.23$ & $1.43 \pm 0.4$ & $1.21 \pm 0.18$ & $0.63 \pm 0.35$ & $0.30 \pm 0.20$ & 86.6 \\
\hline 4 & $\begin{array}{l}\text { Zinc } \\
\text { ointment }\end{array}$ & $2.08 \pm 0.27$ & $1.32 \pm 0.54$ & $1.30 \pm 0.48$ & $1.10 \pm 0.29$ & $0.63 \pm 0.19$ & 69.7 \\
\hline 5 & Argosulfan & $2.55 \pm 0.04$ & $2.10 \pm 0.14$ & $1.56 \pm 0.47$ & $1.32 \pm 0.18$ & $0.72 \pm 0.17$ & 71.8 \\
\hline 6 & Control & $2.55 \pm 0.26$ & $2.38 \pm 0.36$ & $2.24 \pm 0.44$ & $1.68 \pm 0.21$ & $1.00 \pm 0.09$ & 60.7 \\
\hline
\end{tabular}

This gave us the basis for further studies of the effectiveness of the developed nanocomposite ointment in the treatment of burn wounds in dogs.

The study of the wound-healing effect of drugs showed that the regeneration process took place in animals in different ways. It was found that at the first stages of treatment of wounds, the dynamics of their healing was manifested brighter in patients treated with ointment based on silver and zinc oxide nanoparticles, and in the treatment of dogs with "Argosulfan", healing was slower.

On the third day, after the wound, we observed in patients treated with our ointment, moderate swelling of the tissue, while in other patients, these indicators were manifested on the fifth day after the start of treatment. At the same time, the soreness and increase in local temperature still persisted. Turned into a liquid state, dead tissues and some impurities are removed from the body in the form of purulent exudate, which was excreted from the wound into the external environment.

Have dogs with experienced pattern ointment, ranging with 5-6 days after starters treatment wounds, noted gradual the disappearance of inflammatory edema, reducing Tiananmen wound the surface, smoothing wounds with levels skin. By 10-11 days, wound cleansing from necrotic tissues was completed and the formation of a granulation barrier began. Full wound healing was observed by 15-16 days. Have dogs, which enforced "Argosulfan" similar results were forthcoming on 2-3 days later. The disappearance of inflammatory edema and a decrease in the area of the wound surface was noted by day $8-9$, the process of cleansing the wound from necrotic tissues and the formation of a granulation barrier occurred starting from day 13-15, and full clinical recovery by day $18-19$

\section{Discussion}

The obtained results allow us to conclude that in the treatment of burn wounds in dogs, the optimal method of applying ointment based on silver and zinc oxide nanoparticles.

It is established that the number of dogs entering veterinary treatment centers with 
open skin lesions remains at a high level. This makes it expedient to search for and develop advanced and innovative means of stimulating regenerative and reparative processes in tissues.

In the treatment of dogs with wounds of various etiologies ointment based on silver nanoparticles and zinc oxide can be used as a highly effective means for reparative and regenerative therapy.

The studies of the dynamics of hematological and biochemical parameters of blood in experimental animals in the treatment of wounds with ointment based on silver nanoparticles and zinc oxide showed that the main hematological and biochemical parameters in animals, differences with the normative indicators do not have. Thus, the developed ointment does not have an irritating effect, is not toxic and does not have an allergenic effect.

On the basis of the conducted researches it is possible to conclude that the offered ointment on the basis of nanoparticles of silver and zinc oxide possesses osmotic activity, improves drainage of a wound, possesses the expressed prolonged medical, namely anti-inflammatory, antimicrobial, regenerating action.

\section{Conclusions}

- $\quad$ Thus, the new ointment composition for treatment of wounds, including burns, comprising the active substances in the form of nanoparticles of silver and zinc oxide, meets the demanded chemical, medical and biological requirements, ensuring therapeutic effect.

- The studies showed that the ointment composition has good regenerating, antioxidant and wound healing properties due to active proliferation of epithelial tissue in the wound defect area and complete integumentary structures regeneration. Such effect is ensured by the additional components of the ointment, such as glycerin and methyl cellulose, promoting the penetration of active components into the deep panniculus, ensuring the optimal therapeutic effect.

- The ointment composition has sufficient permeability to oxygen and carbon dioxide, thus promoting microcirculation improvement in the wound defect and creates providing conditions for complete regeneration of the damaged tissue.

- The ointment composition is elastic, which allows its use for the surfaces with composite relief.

- It has not local irritant and allergic effect.

\section{References}

1. A. Errokh, A. Magnin, J.-L. Putaux, S. Boufi, Materials Science and Engineering, 105, 110044 (2019)

2. A.W. Jatoi, H. Ogasawara, I.S. Kim, Q.-Q. Ni, Applied Nanoscience (Switzerland), 9, 8, 1661-1670 (2019)

3. A.B. Shatan, K. Venclíková, B.A. Zasońska, V. Patsula, O. Pop-Georgievski, E 
Petrovský., D. Horák, Pharmaceutical Research. 36, 10, 147 (2019)

4. D. Perevezentseva, E. Gorchakov, D. Fedotova, V. Bimatov, E. Triphonova, Key Eng. Mater.: Scientific Journal, 743, 287-291 (2017)

5. A.W. Jatoi, I.S. Kim, H. Ogasawara, Q.-Q. Ni, Materials Science and Engineering, 105, 110077 (2019)

6. A. Dumbrava, D. Berger, C. Matei, G. Prodan, F. Aonofriesei, M.D. Radu, F. Moscalu, Journal of Inorganic and Organometallic Polymers and Materials. 29, 6, 2072-2082 (2019)

7. D.O. Perevezentseva, E.A. Vaitulevich, V.V. Bimatov, Oriental J. of Chem.: Research Journal, 34, 2, 1130-1135 (2018)

8. Andrey Korshunova, Michael Heyrovsky', Electrochim. Acta, 54, 6264-6268 (2009)

9. D.O. Perevezentseva, E.V. Gorchakov, Yu.A. Oskina, Key Engineering Materials: Scientific Journal, 712, 117-122 (2016)

10. D. Perevezentseva, E. Gorchakov, M. Petrushin, I. Hismutdinov, V. Bimatov, AIP Conference Proceedings, 1772, 020005 (2016)

11. Guidefor the Care and Use of Laboratory Animals. - Washington: National Academy Press, 1996., Letter of the Resident of the Russian Federation dated January 3, 2000 N Pr-6 //Federal Law Project Charter N 97.802.1632 Consultant, Legal Framework.

12. M.I. Kuzin, B.M. Kostyuchenok, Rany i ranevaya infectsiya,.552 (1990)

13. B.S. Vikhriyev, V.H. Zhizhin, E. Baking, Big Medical Encyclopedia. Burns, (2019) 